\title{
Artigos
}

\section{Narrativas de viajantes: encontro de pesquisadores de campo com novas escolas médicas federais do Brasil*}

Travelers' narratives: field researchers meet new Brazilian federal medical schools (abstract: p. 17)

Narrativas de viajeros: encuentro de investigadores de campo con nuevas escuelas médicas federales de Brasil (resumen: p. 17)

Willian Fernandes Luna(a)

$<$ willianluna@gmail.com> (iD)

Daniele Cristina Godoy ${ }^{(b)}$

<dani.god@uol.com.br> iD

Carolina Siqueira Mendonça ${ }^{(c)}$

<siqueira.carol@uol.com.br> iD

Fabíola Lucy Fronza Alexandre ${ }^{(d)}$

$<$ fabiolafronza.alexandre@gmail.com> (iD

Eliana Goldbarb Cyrino(e)

<eliana.goldfarb@unesp.br>
* Artigo resultado de pesquisa financiada pelo Ministério da Saúde brasileiro e pela Organização Pan-Americana de Saúde (OPAS) - Brasil.

(a) Departamento de Medicina, Universidade Federal de São Carlos. Rodovia Washington Luís, km. 235, SP-310. São Carlos, SP, Brasil. 13565-905.

(b) Centro de Saúde Escola, Faculdade de Medicina de Botucatu (FMB), Universidade Estadual Paulista Júlio de Mesquita Filho (Unesp). Botucatu, SP, Brasil.

continua pág. 14

O eixo Formação do Programa Mais Médicos estimulou a implantação de novos cursos de Medicina em universidades federais no Brasil. Nesse contexto, um projeto interinstitucional buscou mapear essas escolas médicas, propiciando espaços formativos na perspectiva do amigo crítico. Este artigo apresenta uma pesquisa qualitativa que analisou as experiências de nove viajantes - pesquisadores de campo - em suas visitas realizadas às novas escolas, por meio desse projeto, em 2018. Foi realizada análise temática do conteúdo de 21 narrativas dos viajantes, surgindo três categorias temáticas: expectativas, encontro com desconhecidos e despedidas. Uma narrativa coletiva foi tecida a partir das diversas experiências e relações vivenciadas pelos viajantes, na qual emergiram riqueza e singularidades de cada escola visitada, com destaque para uma pesquisa ética e comprometida. A análise reforça a possibilidade do uso de narrativas de pesquisadores de campo para agregar subjetividades às investigações sobre a realidade vivida.

Palavras-chave: Educação médica. Narrativa. Programa Mais Médicos. Instituições de ensino superior. Saúde Pública.

Luna WF, Godoy DC, Mendonça CS, Alexandre FLF, Cyrino EG. Narrativas de viajantes: encontro de pesquisadores de campo com novas escolas médicas federais do Brasil. Interface (Botucatu). 2020; 24 e190893 https://doi.org/10.1590/Interface.190893 


\section{Introdução}

$\mathrm{Na}$ maioria dos países do mundo, as desigualdades no acesso aos serviços de saúde têm sido apontadas como um grave problema persistente ao longo do tempo e resistentes a variadas estratégias adotadas para seu enfrentamento ${ }^{1}$. Regióes geográficas mais isoladas e afastadas dos grandes centros e populaçóes mais pobres estão mais vulneráveis à insegurança assistencial em saúde ${ }^{1,2}$. Nesse contexto, a aproximação entre serviços de saúde e formação médica pode favorecer respostas às necessidades da população, como na Austrália e no Canadá, onde há inserção de escolas médicas em regiões ditas remotas, objetivando-se ampliar o acesso à assistência médica ${ }^{2,3}$.

No Brasil, foram propostas diversas iniciativas para enfrentar essas questóes no Sistema Único de Saúde (SUS); entretanto, nenhuma delas teve a abrangência, magnitude e agilidade do Programa Mais Médicos (PMM), constituído por três eixos: Provimento Emergencial, Infraestrutura e Formaçãó ${ }^{4}$.

O eixo Formação do PMM trouxe a proposição de um elenco de ações de mudanças na educação médica ${ }^{5}$. Estudiosos desse campo dedicaram-se a investigar essas açôes, potencialidades e impactos na formação dos profissionais médicos pós-PMM, entre os quais pôde-se perceber a expansão de vagas em cursos de Medicina; a criação de novos cursos de graduação no interior do país, inclusive em universidades federais; a adoção de diferentes dispositivos para a mudança na formação, com destaque para as novas Diretrizes Curriculares Nacionais (DCN) para os cursos de graduação em Medicina ${ }^{6}$; o ensino centrado na atenção primária em saúde, na perspectiva da clínica ampliada e da integralidade do cuidado; e a valorização da formação e do desenvolvimento dos docentes e preceptores nas escolas médicas ${ }^{7-9}$.

Como até o ano de 2017 poucos eram os estudos sobre a implantação dessas novas escolas médicas em universidades federais, construiu-se interinstitucionalmente o projeto "Avaliação do desenvolvimento da dimensão Formação para o SUS no PMM: Mapeamento das ações de expansão de vagas, da criação de novos cursos e da implantação das DCN" (projeto Mapeamento) ${ }^{10}$.

\section{O projeto Mapeamento}

Desenvolvido em 2017 e 2018, teve como objetivo mapear a criação de novas escolas médicas federais e a implantação das DCN de 2014. Pautou-se na construção de um método que permitisse aproximação aos processos vivenciados nas realidades dos $\operatorname{cursos}^{10}$, contemplando análise documental e trabalho de campo, por meio de visitas a essas novas escolas. Durante as visitas, a postura adotada pelos pesquisadores de campo era a de um amigo crítico $^{11}$, como alguém que tem uma visão distanciada do processo vivenciado, mas que estudou sobre a escola e está comprometido com a situação e o apoio às instituiçóes, favorecendo a reflexão sobre potencialidades, desafios e necessidades.

Nas visitas, havia conversas com coordenadores, docentes e estudantes dos cursos, dirigentes das instituições e representantes dos serviços de saúde, com preenchimento de instrumentos do projeto. Além disso, os pesquisadores de campo escreviam uma narrativa reflexiva sobre a experiência vivida no encontro com a escola. Narrativas não 
interessadas em transmitir o "puro em si”, como uma informação ou um relatório, mas mergulhadas nas vivências dos narradores ${ }^{12}$.

O projeto Mapeamento levantou que, de um total de cerca de oitenta cursos de Medicina em universidades federais, trinta foram cursos implantados entre $2013 \mathrm{e}$ 2017 no âmbito do PMM. Essas novas escolas médicas localizam-se fora das capitais dos estados, nas cinco regiões geográficas brasileiras e em cidades em que não havia nenhum curso público de Medicina. Pôde-se observar que as escolas estão organizadas em arranjos formativos diversos e buscam superar a fragmentação disciplinar, com metodologias ativas, avaliação formativa e incipiente articulação com pesquisa e extensão. Utilizam a rede de atenção na formação e valorizam a integração ensinoserviço-comunidade, na busca de uma formação crítica e voltada ao SUS. A formação docente carece de incentivo e há experiências de estímulo ao ingresso de estudantes locais e criação de residências médicas, expedientes potentes à fixação médica.

Para além desses resultados, outros questionamentos surgiram no sentido de compreender como haviam sido as experiências vividas pelos pesquisadores de campo com as novas escolas médicas e seus atores, a partir das narrativas redigidas durante o projeto Mapeamento. E é a partir da perspectiva desses textos narrados que nasceu este artigo, que traz a riqueza do olhar dos pesquisadores, aqui chamados de viajantes, sobre suas relaçóes no campo de pesquisa.

\section{Metodologia}

Este foi um estudo exploratório sobre as experiências dos viajantes no campo de pesquisa do projeto Mapeamento, a partir de suas narrativas. Optou-se pela abordagem qualitativa, compreendendo-a como a mais adequada para discutir as experiências, posicionamentos, perspectivas e subjetividades vivenciadas pelos pesquisadores de campo no encontro com as diversas escolas ${ }^{13,14}$.

Durante o projeto Mapeamento, foi possível visitar 24 dos trinta novos cursos de Medicina identificados. Cinco cursos não foram visitados devido à incompatibilidade de agendas, indisponibilidade das escolas ou questóes logísticas. Essas visitas foram realizadas no segundo semestre de 2018 por nove viajantes selecionados para participar devido às suas experiências com educação médica. Eram sete do gênero feminino e dois do masculino, com idades que variavam entre 35 e 55 anos. Entre as ocupaçóes, havia três enfermeiras, dois médicos, uma fisioterapeuta, uma psicóloga, uma pedagoga e uma bióloga.

Nesse contexto, foi solicitado que cada viajante redigisse uma narrativa logo após a visita à escola médica, em formato livre, apontando reflexóes sobre a experiência da visita. Não havia um formulário próprio e a recomendação é que fossem registradas memórias sobre as impressóes e sensaçôes provenientes da convivência com o campo da pesquisa. Cabe destacar que as narrativas não estavam previstas no início do projeto Mapeamento, mas foram introduzidas no decorrer da pesquisa com o objetivo de incluir aspectos experienciais e subjetivos na construção de dados.

A experiência aqui foi entendida por meio do conceito de Larrosa Bondía como aquilo que transforma o sujeito que a vive, não sendo apenas o que acontece, mas o que o toca ${ }^{15}$. Já a narrativa foi compreendida a partir da visão de Walter Benjamin, em 
uma relação entre experiência, tempo e memória; e em um ato de narrar que não busca ser um romance, nem um relatório, mas uma história tecida da própria reminiscência ${ }^{12}$. A narrativa é uma forma artesanal de comunicar as experiências na forma de histórias, que evidenciam aspectos antes desconhecidos e que podem representar a experiência individual e coletiva ${ }^{16}$. Utilizando-se a orientação teórica dos estudos narrativos, aponta-se também para a contribuição sobre as relaçóes entre estrutura e ação social e, no caso específico da saúde, as narrativas podem ser vistas como elementos centrais para construção da experiência ${ }^{17}$.

No total, somaram-se 21 narrativas de viajantes incluídas neste estudo. Um viajante enviou a narrativa em áudio, tendo sido excluída dos materiais por tratar-se de uma estrutura diferente da narrativa escrita. Não foram enviadas narrativas em duas visitas. Para garantir a confidencialidade das informaçóes, conforme assumido no compromisso ético desta pesquisa, foi atribuído um número aleatório a cada uma das escolas e nomes fictícios aos viajantes.

A exploração do material foi realizada pelos autores deste artigo seguindo-se as recomendaçôes da análise temática de conteúdo ${ }^{18}$, com os seguintes momentos: 1) Préanálise com imersão nas narrativas; 2) Construção de mapas conceituais individuais sobre os principais aspectos narrados nos materiais; 3) Apresentação dos mapas em reunião, somada aos objetivos desta pesquisa e resgate dos outros resultados do projeto Mapeamento, possibilitando a construção coletiva de pré-categorias de análise relacionadas aos momentos vivenciados na experiência; 4) Recortes das narrativas e seu ordenamento, relacionando-os às pré-categorias e constituindo-se núcleos de sentido; 5) Elaboração final das categorias temáticas, com os procedimentos de categorização, inferência, descrição e interpretação ${ }^{18}$.

Finalizou-se discutindo os resultados com referenciais teóricos relacionados. Em todo processo, utilizou-se partes selecionadas das narrativas dos viajantes na elaboração de um tecido narrado, não no sentido de trazer o que se narrou de cada encontro, mas a partir do que se selecionou para narrar.

Esta pesquisa foi aprovada pelo Comitê de Ética em Pesquisa da Faculdade de Medicina de Botucatu - Universidade Estadual Paulista, sob CAAE n.

88186418.7.0000.5411.

\section{Tecido narrado}

As vivências dos viajantes registradas em suas narrativas individuais possibilitaram a construção de uma narrativa coletiva no sentido de reelaborar os encontros com as novas escolas médicas, aflorando três momentos principais dessa experiência: expectativas e contatos à distância; encontro com os desconhecidos; e despedidas e reflexões pós-visita. 


\section{As expectativas e os contatos a distância}

As expectativas narradas pelos viajantes iniciaram-se no período de planejamento e organização da visita. A espera era pelo aceite, pelo deixar-se entrar. A definição pela escola a ser visitada, às vezes, não se dava por acaso, mas sim por algo que de certa forma já sensibilizava o pesquisador e o movia à tal instituição. Em um primeiro momento, cada futuro viajante realizava o contato com a coordenação do curso e iniciava um processo de planejamento, buscando a primeira aproximação com os campos a serem visitados, em uma construção que pudesse apreender a realidade, trazendo a convergência de vários pontos de vista, pois o trabalho de campo é uma possibilidade de aproximação com o que se deseja conhecer e estudar ${ }^{14}$.

$\mathrm{Na}$ leitura e análise das narrativas, alguns viajantes relataram que, desde o início, foram bem acolhidos pelos coordenadores e conseguiram, nas poucas (ou muitas) trocas de correio eletrônico e telefonemas, apresentar os objetivos da pesquisa, agendar e organizar uma programação para a visita:

Quando liguei, a receptividade foi grande e logo conseguimos encontrar uma data possível para a visita. Enviei os documentos, recebi e-mails com informaçóes sobre o curso, instituição e dúvidas sobre as atividades a serem realizadas, e juntos construímos uma programação para três dias. (E17 - Nuno)

Iniciei um diálogo via e-mail com o coordenador, apresentei o projeto, convidei-o a participar da pesquisa; ele prontamente se colocou à disposição e abriu a porta para pesquisa. (E6 - Joana)

Porém, alguns viajantes se depararam com certa resistência para o agendamento, gerando algum sentimento de frustração, mas também de motivação para a elaboração de caminhos possíveis a partir das próprias expectativas e das necessidades e possibilidades das escolas:

Pré-agendamos a visita. Mas quando apresentamos a proposta de roteiro, a coordenadora nos respondeu que não teriam como organizar a visita conforme nossas expectativas, pois estavam com uma sobrecarga de trabalho e com outros compromissos já assumidos. Seria possível apenas realizarmos conversas/ entrevistas com os atores que, porventura, estivessem no campus na ocasião da visita. Avaliamos junto à coordenação da pesquisa que, mesmo com os extensos deslocamentos até lá e com uma agenda reduzida, era importante conhecer a realidade desta escola. (E18 - Acácia)

Foram inúmeras tentativas sem nenhum sucesso. Ligações perdidas em meio às inúmeras transferências que não me direcionavam a lugar nenhum. Depois de muita insistência, uma secretária resolveu me atender e começou a responder aos meus e-mails. Mas para a minha surpresa, com a visita já agendada, passagens compradas, tudo certo, recebo um telefonema, questionando sobre a visita. (E10 - Roberta) 
Contatos iniciais feitos, visitas programadas, roteiros pré-agendados, passagens em mãos e lá foram, para as cinco regiões do país, os viajantes que sentiram na pele as longas travessias para se chegar aos locais escolhidos para a implantação das escolas médicas federais. Pesquisadores de uma realidade a mapear, em nome de um projeto de saúde implicado com os direitos da sociedade brasileira, buscando os sentidos das lutas, das conquistas e das desistências e resistências, ora involuntárias, ora intencionais:

O caminho é longo do aeroporto até a Ponta da Espera, local de embarque no Ferry Boat. Foram duas horas e meia de viagem observando a paisagem e desfrutando da brisa que nos refrescou naquela tarde quente. Ao desembarcarmos do "ferry" enfrentamos mais uma hora e meia de viagem por uma estrada estreita, pouco sinalizada e bastante movimentada. (E12 - Roberta)

A visita iniciou com uma grande dificuldade de planejamento da logística. Com poucos vôos para a cidade, chegar até lá, em meio à Amazônia, partindo de uma cidade do interior de São Paulo demandou um deslocamento de 36 horas. O retorno não foi diferente. (E1 - Nuno)

A visita constituía em momento para aprender a ver, a ouvir e a falar com as pessoas, em uma postura de um pesquisador que tivesse o perfil de conversador ${ }^{19}$, quando há um diálogo horizontal na postura de compartilhamento, e não de uma relação distanciada sem considerar as realidades objetivas locais e os contratempos que as comunidades dos cursos enfrentam. Nesse sentido, as narrativas evidenciaram sujeitos carregados de receios, ansiedades e esperanças, que vão ao encontro de outros sujeitos envolvidos na construção de outra realidade de saúde:

As expectativas eram imensas com relação a nossa atividade, tanto por parte da Universidade que estava a nossa espera, quanto a nossa. (E12 - Roberta)

As visitas sempre nos deixam ansiosos. Um longo percurso, a chegada a um local desconhecido e no qual acontecerão muitos encontros. (E8 - Roberta)

Havia em mim certa inquietude por não conhecer o município e a universidade. Meu principal objetivo era apreender, através das sutilezas, como tinha se dado o processo de implantação do curso de medicina e como o mesmo tem se estruturado, a fim de provocar mudanças na formação médica de seus futuros profissionais. (E20 - Maria)

As expectativas foram muito descritas nas narrativas, pois a visita se tratava de um espaço importante para reconhecer as formas criativas - ou não - que as instituições construíram para aderência às DCN e ao eixo Formação do PMM, que é central nessa política pública imbricada com a expansão de cursos médicos em regiôes distantes dos grandes centros urbanos e carentes de escolas de Medicina. 


\section{O encontro com desconhecidos}

Após longos deslocamentos, os viajantes se encontraram com desconhecidos lugares e atores. Desconhecidos contextos brasileiros que afetaram os viajantes. Nesse ínterim, o pesquisador a todo tempo fazia o exercício de aproximação e distanciamento, buscando olhar para a realidade visitada de maneira a não deformar ou obscurecer seus julgamentos e conclusóes ${ }^{20}$.

E neste sertão castigado pela seca e distante da capital foi implantada uma escola médica multicampi, que funciona em quatro cidades da região. (E7 - Roberta)

A cidade é um verdadeiro museu a céu aberto. A beleza arquitetônica barroca, presente em cada detalhe de suas casas e igrejas, se confunde com a crueza dos resquícios da escravatura do Brasil colonial. Em meio a isso, é uma cidade tipicamente universitária, demonstrado sobretudo por um grande movimento de alunos e repúblicas estudantis, o que traz jovialidade misturada a tantos anos de história. (E19 - Maria)

Aos poucos, nas descobertas e nos encontros, esses desconhecidos foram tornandose familiares, à medida que foram ganhando materialidade, rostos, formas, contextos e histórias expressos nas narrativas dos viajantes, material denso e rico que permitiu o reviver de cada uma das viagens ${ }^{20}$. Na maioria das vezes, a coordenação do curso foi a primeira a ser encontrada, com objetivo de planejar as atividades a serem realizadas na visita:

Já haviam me falado sobre a simpatia e a afetuosidade do povo mineiro e isso pôde ser confirmado quando rapidamente me encontrei ao lado da sala da coordenação, me apresentando ao secretário, "velho conhecido" dos contatos prévios por telefone. (E20 - Maria)

Fui recebido já no aeroporto, num domingo, pela vice coordenadora que, junto de outro professor, foi me recepcionar. A acolhida foi bastante calorosa, em meio ao frio de 8 o C que fazia naquele dia. (E15 - Nuno)

Os pesquisadores se encontraram com escolas que funcionavam em espaços doados ou próprios, dentro de um campus universitário exclusivo ou já existente, em estruturas antigas ou novas, locais improvisados ou de fino acabamento e com bons equipamentos ou com carência desses. Nas narrativas dos viajantes, essa diversidade de realidades foi descrita:

Chegando na Universidade, já ouvi do motorista que aquele seria o prédio da Medicina, mas que a construção estava parada há dois anos. Avistei o prédio e me impressionei com o tamanho e destaque frente aos demais blocos dos outros cursos da saúde [...] A coordenadora foi me explicando, enquanto caminhávamos, que eles usavam salas emprestadas, sem ter nenhum espaço somente deles. (E17 - Nuno) 
Eu ainda extasiada pela explicação, concordando não se tratar de algo comum, tendo diante de mim aquele prédio grandioso, com acabamento em mármore e granito, novíssimo, tudo limpo e brilhante, elevadores modernos. (E14 - Sueli)

Encontro um campus no centro da cidade, com alguns cursos de exatas, licenciaturas, um curso de etnodiversidade, além do curso de Medicina, que possui até o momento três turmas. $\mathrm{O}$ curso ainda jovem, mas que já conseguiu ter uma estrutura física interessante, apesar de bem pequena. [...] Recebeu colaboração financeira como contrapartida pela construção da usina. (E1 - Nuno)

As conversas com os docentes e com o Núcleo Docente Estruturante (NDE) foram oportunidades para repensar a formação médica de acordo com as $\mathrm{DCN}^{7}$ e dentro da proposta do PMM, conforme descrito nas experiências de algumas dessas escolas ${ }^{7,9}$. Com os docentes, ao mesmo tempo em que os viajantes os percebiam retraídos e ariscos, também foi possível observar entusiasmo com a possibilidade de serem ouvidos. A maioria dos encontros foram reveladores, com valorização e potência heterogêneos, de acordo com a adesão do grupo:

Os professores se mostraram comprometidos com a formação dos estudantes. Alguns se mostraram receptivos à proposta enquanto outros se mostraram resistentes. Os docentes refletiram sobre os principais obstáculos que eles e a escola enfrentam no seu cotidiano, além de elucubrarem sobre as suas potências. (E13 - Lia)

À noite me reuni com o NDE e os representantes de turma. A pedido do coordenador do curso, além das perguntas disparadoras, realizamos uma conversa focada nas atribuições do NDE. O grupo de professores estava muito animado com a conversa. Eles puderam trazer para o diálogo suas dificuldades, suas frustraçóes, além de propostas sobre metodologias ativas. (E11 - Lia)

O que me chamou a atenção na conversa com os professores foi um pouco da alienação frente à proposta de expansão e interiorização dos cursos de Medicina. Eles me passaram a impressão de desconhecimento da origem do curso, ou seja, na contemplação do eixo do "Mais Médicos". (E8 - Roberta)

Como trabalhadora do SUS há 30 anos, foi uma deliciosa surpresa ouvir, ao "desligar o gravador", professores e alunos trazerem à tona que o que importa mesmo é o "ensinar e aprender com afeto e com emoção". (E20 - Maria)

O encontro com os gestores e os trabalhadores dos serviços de saúde que participavam da formação dos estudantes de Medicina aconteceu nos cenários de prática. As pessoas que compunham os serviços mostraram-se acolhedoras e sedentas por falar. Nas 
narrativas, os viajantes descreveram profissionais que se sentiam satisfeitos por poderem participar desta nova trajetória da educação médica, mas também havia aqueles que não viam significado na formação em serviço. Com os gestores de saúde, ficou evidente que a integração ensino-serviço era um grande desafio, sujeito às instabilidades das instituições locais e em permanente processo de construção ${ }^{21}$, semelhante ao relatado no estudo sobre uma dessas instituições?.

O hospital está movimentado, com pacientes e alunos em atividade prática. Eu e o professor pudemos conversar, sendo que o tema de destaque foi o desafio e o prazer sentido por ele na atuação como docente [...]. Atribuiu esta motivação ao contato com os alunos, impulsionando-o para o estudo e à busca por formação complementar. Falou da importância de criação de um curso médico na região, pois existe uma grande população com muitas necessidades de assistência à saúde e a região tem grande dificuldade de fixação do profissional médico formado nos grandes centros. (E9 - Sueli)

A rede é uma fragilidade dentro da proposta. O diálogo é bom, mas na prática as coisas não funcionam bem. Há queixas dos alunos com relação a receptividade e papel dos preceptores. A maior dificuldade acontece nos serviços de média e alta complexidade, pois muitos profissionais não aceitam a presença dos alunos. [...] O coordenador da Atenção Básica do município nos recebeu com muita agressividade e antipatia. Ele já iniciou a conversa dizendo que ter uma faculdade de medicina no município não muda nada da sua realidade. (E8 - Roberta)

Vi o trabalho vivo e presenciei o vínculo [...]. Acho que nesse momento me senti em casa e com a confiança de que o que importa mesmo está além dos muros da Universidade. Saio de lá com a vontade de "gritar" que a casa adaptada, com a “presença do Seu José, da Dona Maria” ainda é o melhor cenário de ensino que eles possuem e que esse encontro é precioso. (E20 - Maria)

As rodas de conversa com os estudantes foram descritas como o "melhor encontro". Provocadores e participantes, os estudantes desejavam falar e ser ouvidos. $\mathrm{O}$ encontro com esse grupo era sempre valorizado e acontecia "sem filtro", de maneira sincera, em um reconhecimento do espaço como uma possibilidade de troca de experiências, bem como de reconhecer as expectativas e conhecimento desses atores diante deste novo cenário proposto pelas $\mathrm{DCN}^{22}$. Estudantes de todos os lugares do Brasil - com alguns poucos estrangeiros - representando uma grande diversidade cultural, étnica, socioeconômica e de idade mostraram seu empoderamento na construção das escolas:

Para situar o encontro com os estudantes veio a minha mente a canção de Milton, tão cantada, tão atual. "Quero falar de uma coisa...” o encontro com os estudantes demarcou o ponto alto da visita. Havia encantamento, renovação de esperança, traduzida na voz daquela juventude que transpirava amor, desejo de luta por um mundo mais justo. Tudo sem filtro. (E6 - Joana) 
Tive a oportunidade de me sentar com dois representantes de cada ano. As informações vão se confirmando, há críticas com relação a falta de padronização do método utilizado no processo de ensino aprendizagem, ao descompasso entre a metodologia de ensino e o método avaliativo. Os alunos ressentem-se muito com a fragilidade dos campos de estágio, ficam temerosos pelo fato de terem tão pouco espaço dentro dos setores secundário e terciário de saúde. (E4 - Roberta)

A conversa com os estudantes foi o melhor momento. Lembro bem de cada um desses momentos em que os olhos brilhavam. (E5 - Vanessa)

Finalizei com os estudantes, que eram de muitas regióes do país, de muitas idades e origens. Dois dos estudantes eram estrangeiros, um paraguaio e uma boliviana. Aos poucos, foram se sentindo mais à vontade e trouxeram discussóes ricas, inclusive sobre a potência de um curso construído com tantos estrangeiros, numa região de fronteira. Penso que essa interculturalidade deva ser cultivada, provocada, para que possa gerar um produto mais complexo e condizente com o propósito da Universidade. (E4 - Nuno)

Esses momentos buscaram dar voz aos diferentes atores dessas histórias para a compreensão do todo. Diferentes sujeitos e cenários trouxeram a complexidade que cerca a implementação dos cursos em escolas médicas que se constroem, vivem, lutam e resistem.

\section{As despedidas e as reflexões pós-visita}

Ao longo das visitas, os viajantes narraram experiências em uma diversidade de relaçôes em campo, possibilitando inclusive comparaçôes e amadurecimento enquanto investigadores. Estar em campo após planejamento e expectativas construídos previamente é oportunidade de readequar e inovar ${ }^{14}$, principalmente a partir do que é vivido:

Pelo que vi e ouvi, termino esta visita bem mais satisfeita do que da primeira vez e acreditando na potência deste curso mesmo com os desafios que eles têm pela frente. (E3 - Acácia)

Finalizo minha terceira visita com a impressão de que aqui, diferente das duas outras escolas que já visitei, os encontros para a pesquisa foram menos potentes para eles, talvez pela dificuldade de planejamento compartilhado. Mas fui readequando de acordo com o que foi necessário, tentando torná-la potente. (E15 - Nuno)

Como narrado neste último trecho, algumas visitas foram marcadas por resistências e dificuldades, na maior parte das vezes geradas por um planejamento que não foi construído de forma compartilhada, ou ainda pela compreensão habitual sobre o papel do pesquisador em campo, frequentemente associado a um distanciamento frente aos sujeitos baseado em princípios cartesianos de neutralidade ${ }^{23}$. 
Bom, não preciso dizer que a minha passagem pela instituição também se deu com resistência, um ambiente de muita desconfiança que me deixou bastante desconfortável. A todo momento a secretaria me conduzia e me anunciava como a pesquisadora vinda para "coletar" dados para a minha pesquisa. (E10 - Roberta)

O encontro entre os então desconhecidos também foi narrado como espaço de aprendizagem para além de uma visita de coleta de dados, o que se relacionou à proposta do projeto Mapeamento, que foi a de ter um pesquisador de campo como um "amigo crítico", provocando reflexões e identificação de potencialidades e fragilidades entre os atores locais. Uma visita pautada em um encontro que permitiu a cooperação e a colaboração, com partilha de ideias e experiências ${ }^{11}$ :

O coordenador começou a se entusiasmar, naquele momento se deu conta de que nossa presença era para além de coletar dados de pesquisa, mas era formativo e poderia contribuir para o curso. Externou que fazia tempo que não se sentia assim. Ouvir-nos estava trazendo alento para ele frente a tantas dificuldades enfrentadas. (E6 - Joana)

Segundo eles, a visita promoveu uma força extra propulsora que eles estavam precisando. Eles sentem-se isolados, sem saber como andam as demais escolas. (E13 - Lia)

Nesse contexto, alguns viajantes receberam agradecimentos dos atores locais, pois a visita pôde ser reconhecida como formativa, diferente de visitas de avaliação institucionais que por vezes não realizam construçôes nesse sentido. O encontro do curso com alguém que era da área, mas que estava em outra realidade, pôde oportunizar troca de saberes no movimento de reconhecimento e cumplicidade ${ }^{11}$.

$\mathrm{Na}$ avaliação geral sobre a visita realizada com a coordenação do curso, fizeram questão de agradecer e reforçar que os momentos foram muito produtivos e que ajudarão no processo de desenvolvimento do curso de Medicina. Finalizou retomando um sentimento compartilhado com estudantes: "Que bom que você veio. Estamos abandonados”. (E21 - Nuno)

O coordenador do curso agradeceu muito a visita e finalizamos verbalizando a nossa concordância com relação à importância de se investir esforços para a construção e consolidação de uma formação médica de qualidade. (E2 - Sueli)

A partir da visita, os viajantes relataram aprendizados que foram por eles construídos a partir da imersão na realidade de uma nova escola de Medicina, em um ato de aprendizado a partir da experiência vivida, e não da neutralidade de um experimento controlado ${ }^{15}$.

Volto para Botucatu com maior conhecimento sobre a docência no Brasil, para longe dos muros do sudeste. (E16 - Lia) 
Considero como potencialidade da visita o fato de a aprendizagem também ter sido minha. Aprendi com a indiferença que cedeu lugar ao agradecimento e amenizou o sentimento de frustração até então sentido. (E6 - Joana)

Quando me perguntaram, respondi que aprendi muito e tive o privilégio de ver um exemplo de seriedade, liderança e de dedicação ao trabalho, que somente poderia resultar em todo o merecido respeito que pude presenciar em muitas situaçôes durante estes dois dias. (E14 - Sueli)

Os viajantes afetaram-se e foram provocados a reflexóes sobre o papel dessas novas escolas médicas e seus atores nas regióes visitadas. Diferente de estratégias de coleta ou construção de dados que buscam a neutralidade do pesquisador, aqui fica evidente que o investigador também está implicado e reconhece na investigação uma possibilidade ética de construção de uma sociedade justa e democrática ${ }^{24}$.

Conseguimos visualizar, sentir, a força e a vontade de se construir uma formação médica de qualidade em uma região tão carente, não somente de recursos médicos e de saúde, mas carente de infraestrutura básica [...], nesta formação médica para "além do ferry", como costumam dizer. (E12 - Roberta)

Inicio o retorno, mas não posso dizer que com tranquilidade, pois com todas as informaçốes que ouvi fica a certeza de que o caminho pode ser longo, pois tudo tem sido construído com muita luta para que o curso resista. (E18 - Acácia)

Finalizo essa visita com um sentimento de entusiasmo e preocupação, pois um curso tão potente necessita de mais colaboração externa para que possa se manter comprometido com a formação de profissionais que podem impactar a realidade de saúde local. (E21 - Nuno)

Os viajantes destacaram ainda que essas novas escolas estão mais próximas de grupos sociais e regiôes geralmente excluídos dos cursos de Medicina. Nesse sentido, para além do contexto da pesquisa realizada, eles também foram afetados para outras complexidades da sociedade brasileira, em seu caminho para a superação das desigualdades e o desafio da construção de cidadania.

A conversa com os estudantes indígenas e quilombolas me provocou ainda mais, pois apesar de haver um desejo dos professores em propiciar um espaço adequado de aprendizagem, ainda não sabem bem como fazer e acabam esbarrando nas dificuldades previsíveis de fragilidade de formação básica dos estudantes de açôes afirmativas e de poucas estratégias para permanência estudantil. O que e onde precisamos avançar mais? (E21 - Nuno) 
Quem sabe daqui a alguns anos, aos moldes da diversidade de coisas para vender na feira de caruaru, cantada por Gonzagão, seja também um retrato de outra diversidade de ofertas desse novo polo que se constrói: Um Polo de Saúde. (E5 - Vanessa)

A seca é um assunto que circula por todos os cantos: "tem criança aqui de 5 anos que nunca viu chuva. Quando chove todo mundo vai para fora se molhar. Fazemos algumas adaptaçôes e já aprendemos a viver sem chuva”. Numa visita pela cidade foi possível ver as marcas desta seca. (E7 - Roberta)

Estar em meio à Amazônia às margens de um grande rio, deixou-me afetado. Sensível à importância de regionalizarmos os cursos de Medicina, de oportunizarmos formação para populaçôes de regióes remotas, mas principalmente questionando-me sobre como podemos construir um novo conhecimento, legitimamente brasileiro, a partir dos olhares do nosso povo. (E1 - Nuno)

Dessa forma, evidenciou-se que o uso das narrativas na pesquisa qualitativa possibilitou um resgate do sujeito, principalmente de caráter descritivo e etnográfico, e que pôde avançar no sentido de intervenção $0^{25}$. Assim, as narrativas dos viajantes nos reportaram ao próprio ato de investigar e construir ciência, aproximando-se do compromisso social da pesquisa para o bem comum, em um caminho ético e responsável ${ }^{24}$, que possibilitou a ampliação de olhares de todos os envolvidos.

\section{Considerações finais}

Talvez não tenha sido possível trazer toda a poética dos encontros, pois a diversidade de vozes, de vivências, de cheiros e de emoçôes estão para além do que é narrado. Todavia, buscou-se construir uma narrativa coletiva a partir das diversas experiências dos viajantes, na busca de uma aproximação das relações e emoçóes afloradas nos encontros da pesquisa.

Os viajantes puderam experienciar, sob a perspectiva da pesquisa, o estar em campo para realizar, observar, escutar atentamente, conversar e, a partir daí, produzir uma narrativa. Colocaram-se na posição de pessoas interessadas em partilhar as experiências de outras pessoas, com cumplicidade e implicados com a escuta objetiva e singular.

O tecido narrado permitiu descortinar as experiências dos pesquisadores que foram a desconhecidos locais, onde encontraram os protagonistas na criação e desenvolvimento de novas escolas médicas federais, que buscaram estar em consonância com as DCN para atender às necessidades de saúde da população brasileira de acordo com princípios e diretrizes do SUS.

Regióes desconhecidas ao olhar desses viajantes e, por vezes, distantes, foram cenários do encontro com uma diversidade de pessoas, instituições, serviços de saúde, potencialidades e fragilidades da proposta de inovação no ensino médico. Cada vivência, sob o olhar atento do viajante narrador, trouxe o contato com a realidade na qual as novas escolas foram implantadas e se desenvolvem. Cada encontro 
transmitiu os anseios, as dúvidas e as incertezas na construção e desenvolvimento locais. Aproximar-se desses movimentos inovadores e criativos nas diversas localidades reforça a compreensão de que as políticas de incentivo federais foram decisivas para a implantação dos cursos, porém a sua manutenção e capacidade de transformação da realidade de saúde local dependem de uma série de outros fatores.

Destaca-se ainda a possibilidade do uso de narrativas de pesquisadores de campo para agregar subjetividades às investigaçóes sobre a realidade vivida, permitindo a construção de um estudo ético e comprometido com a transformação social.

\section{Filiação}

(c,e) Departamento de Saúde Pública, FMB, Unesp. Botucatu, SP, Brasil.

(d) Faculdade Cosmos de Manaus, Instituto Cosmos de Ensino Superior Ltda. Manaus, AM, Brasil.

\section{Agradecimentos}

Ao Ministério da Saúde do Brasil, que por meio da Carta Acordo SCON 2017 - 02638 financiou a pesquisa. À Organização Pan-Americana de Saúde, que oportunizou a realização desta pesquisa, por meio do financiamento e da construção compartilhada, e pelo incentivo permanente à educação médica no Brasil. Aos interlocutores nas escolas médicas federais e nos serviços de saúde visitados, pela disponibilidade e pelo acolhimento e compromisso na recepção dos pesquisadores de campo.

\section{Contribuição dos autores}

Todos os autores participaram ativamente de todas as etapas de elaboração do manuscrito.

\section{Direitos autorais}

Este artigo está licenciado sob a Licença Internacional Creative Commons 4.0, tipo BY (https://creativecommons.org/licenses/by/4.0/deed.pt_BR).

\section{(cc) BY}




\section{Referências}

1. Kemper ES, Mendonça AVM, Sousa MF. Programa Mais Médicos: panorama da produção científica. Cienc Saude Colet. 2016; 21(9):2785-96.

2. Vanni T, Cyrino AP, Ribeiro ACRC. Provimento médico no sistema de saúde da Austrália: uma conversa com Megan Cahill. Interface (Botucatu). 2017; 21(1):1367-76.

3. Strasser R, Worley P, Cristobal F, Marsh DC, Berry S, Strasser S, et al. Putting communities in the driver's seat: the realities of community-engaged medical education. Acad Med. 2016; 90(11):1466-70.

4. Brasil. Presidência da República. Lei no 12.871, de 22 de Outubro de 2013. Institui o Programa Mais Médicos, altera a Lei no 8.745, de 9 de Dezembro de 1993, e no 6.932, de 7 de Julho de 1981, e dá outras providências. Diário Oficial da União. 23 Out 2013.

5. Oliveira FP, Pinto HA, Figueiredo AM, Cyrino EG, Oliveira Neto AV, Rocha VXM. Programa Mais Médicos: avaliando a implantação do Eixo Formação de 2013 a 2015. Interface (Botucatu). 2019; 23 Supl 1:e170949.

6. Brasil. Ministério da Educação. Resolução CNE/CES no 3, de 20 de Junho de 2014. Institui diretrizes curriculares nacionais do curso de graduação em Medicina e dá outras providências. Brasília: Ministério da Educação; 2014.

7. Vieira RMM, Pinto TR, Melo LP. Narrativas e memórias de docentes médicos sobre o ensino baseado na comunidade no Sertão Nordestino. Rev Bras Educ Med. 2018; 42(1):142-51.

8. Oliveira FP. As mudanças na formação médica introduzidas pelo Programa Mais Médicos [tese]. Brasília: Universidade de Brasília; 2018.

9. Pedrosa JIS. Implantação e desenvolvimento do curso de Medicina em Parnaíba, PI, Brasil, a partir do Programa Mais Médicos para o Brasil. Interface (Botucatu). 2019; 23 Supl 1:e180012.

10. Sordi MRL, Mendes GSCV, Cyrino EG, Alexandre FLF, Manoel CM, Lopes CVM. Experiência de construção coletiva de instrumento auto avaliativo a serviço da formação médica referenciada nas Diretrizes Curriculares Nacionais (DCN) pautadas no Programa Mais Médicos. Interface (Botucatu). 2020; 24:e190527.

11. Leite C. A figura do amigo crítico no assessoramento/desenvolvimento de escolas curricularmente inteligentes. In: Fernandes M, Gonçalves JA, Bolina M, Salvado T, Vitorino T, organizadores. O particular e o global na virada do milênio: cruzar saberes na educação. Lisboa: Editora Colibri, Sociedade Portuguesa de Educação; 2002. p. 95-100.

12. Benjamin W. O narrador: consideraçôes sobre a obra de Nicolai Leskov. In: Benjamin W. Magia e técnica, arte e política: ensaios sobre literatura e história da cultura. São Paulo: Editora Brasiliense; 2012. p. 213-40.

13. Turato ER. Métodos qualitativos e quantitativos na área da saúde: definiç̧óes, diferenças e seus objetos de pesquisa. Rev Saude Publica. 2005; 39(3):507-14.

14. Minayo MCS. O desafio do conhecimento: pesquisa qualitativa em saúde. 9a ed. São Paulo: Hucitec; 2006.

15. Larrosa Bondia J. Notas sobre a experiência e o saber de experiência. Rev Bras Educ. 2002; (19):20-8.

16. Sousa MGS, Cabral CLO. A narrativa como opção metodológica de pesquisa e formação de professores. Horizontes. 2015; 33(2):149-58.

17. Muylaert CJ, Sarubbi JV, Gallo PR, Neto MLR, Reis AOA. Entrevistas narrativas: um importante recurso em pesquisa qualitativa. Rev Esc Enferm USP. 2014; 48(2):184-9. 
18. Castellanos MEP. A narrativa nas pesquisas qualitativas em saúde. Cienc Saude Colet. 2014; 19(4):1065-76.

19. Minayo MCS, Deslandes SF, Gomes R. Pesquisa social: teoria, método e criatividade. 33a ed. Petrópolis: Vozes; 2013.

20. Spink PK. O pesquisador conversador no cotidiano. Psicol Soc. 2008; 20 (spe):70-7.

21. Velho G. Observando o familiar. In: Nunes EO. A aventura sociológica. Rio de Janeiro: Zahar; 1978. p. 123-40.

22. Pinto TR, Cyrino EG. Com a palavra, o trabalhador da Atenção Primária à Saúde: potencialidades e desafios nas práticas educacionais. Interface (Botucatu). 2015; 19(1):765-77.

23. Meireles MAC, Fernandes CCP, Silva LS. Novas Diretrizes Curriculares Nacionais e a formação médica: expectativas dos discentes do primeiro ano do curso de medicina de uma instituição de ensino superior. Rev Bras Educ Med. 2019; 43(2):67-78.

24. Batista NCS, Bernardes J, Menegon VSM. Conversas no cotidiano: um dedo de prosa na pesquisa. In: Spink MJ, Brigagão JIM, Nascimento VLV, Cordeiro MP, organizadores. Práticas discursivas e produção de sentidos no cotidiano: aproximaçốes teóricas e metodológicas. Rio de Janeiro: Centro Edelstein de Pesquisas Sociais; 2014. p. 22-41.

25. Rios TA. A ética na pesquisa e a epistemologia do pesquisador. Psicol Rev. 2006; 12(19):80-6.

26. Onocko CRT, Furtado JP. Narrativas: utilização na pesquisa qualitativa em saúde. Rev Saude Publica. 2008; 42(6):1090-6. 
The Formation axis of the More Doctors Program stimulated the implementation of new medical courses at Brazilian federal universities. In this context, an interinstitutional project sought to map these medical schools, providing training spaces in the perspective of the critical friend. This article presents a qualitative research that analyzed the experience of nine travelers - field researchers - in their visits to new schools, through this Project, in 2018. Thematic analysis of the content of 21 travelers' narratives was carried out, with three thematic categories: expectations; meeting with strangers; goodbyes. A collective narrative was woven from the diverse experiences and relationships experienced by travelers, where the wealth and singularities of each school visited emerged, with emphasis on ethical and committed research. The analysis reinforces the possibility of using narratives by field researchers to add subjectivities to investigations about the lived reality.

Keywords: Medical education. Narrative. More Doctors Program. Higher education institutions. Public Health.

El eje Formación del Programa Más Médicos incentivó la implantación de nuevos cursos de Medicina en universidades federales brasileñas. En este contexto, un Proyecto interinstitucional buscó mapear esas escuelas médicas, propiciando espacios formativos en la perspectiva del amigo crítico. Este artículo presenta una investigación cualitativa que analizó las experiencias de nuevos viajeros, investigadores de campo, en sus visitas realizadas a las nuevas escuelas, por medio de ese Proyecto en 2018. Se realizó un análisis temático del contenido de 21 narrativas de los viajeros, surgiendo tres categorías temáticas: expectativas, encuentro con desconocidos, despedidas. Se tejió una narrativa colectiva a partir de las diversas experiencias y relaciones vividas por los viajeros, donde surgieron riqueza y singularidades de cada escuela visitada, con destaque para una investigación ética y comprometida. El análisis refuerza la posibilidad del uso de narrativas de investigadores de campo para agregar subjetividades a las investigaciones sobre la realidad vivida.

Palabras clave: Educación médica. Narrativa. Programa Más Médicos. Instituciones de enseñanza superior. Salud Pública. 